\title{
Nuclear transcription factor CDX2 inhibits gastric cancer-cell growth and reverses epithelial-to-mesenchymal transition in vitro and in vivo
}

\author{
JIAN-FENG ZHANG ${ }^{1,2}$, LI-SHUAI QU ${ }^{2}$, XUE-FEN QIAN ${ }^{2}$, \\ BEI-LEI XIA ${ }^{2}$, ZHEN-BIAO MAO ${ }^{2}$ and WEI-CHANG $\mathrm{CHEN}^{1}$ \\ ${ }^{1}$ Department of Gastroenterology, The First Affiliated Hospital of Soochow University, Suzhou, Jiangsu 215006; \\ ${ }^{2}$ Department of Gastroenterology, Affiliated Hospital of Nantong University, Nantong, Jiangsu 226001, P.R. China
}

Received October 16, 2014; Accepted July 7, 2015

DOI: $10.3892 / \mathrm{mmr} .2015 .4114$

\begin{abstract}
The epithelial-to-mesenchymal transition (EMT) has been noted as a critical event in the early step of cancer metastasis. Recent studies showed that nuclear transcription factor caudal type homeobox transcription factor 2 (CDX2) is a prognostic factor, which acts as a marker of good outcome in gastric cancer (GC) patients. However, the association between CDX2 expression and EMT has remained to be fully elucidated. The present study reported that forced overexpression of CDX2 in MKN45/CDX2 cells inhibited GC-cell growth and proliferation, and attenuated migration and invasion in vitro. Furthermore, MKN45/CDX2 cells exhibited a significant upregulation of E-cadherin protein and a significant downregulation of vimentin protein expression. These results were further supported by in vivo tumorigenicity assays, which showed that CDX2 suppressed gastric tumor xenograft growth and inhibited EMT in nude mice. These results indicated that CDX2 is capable of inhibiting GC-cell growth and invasion. CDX2 may participate in the process of EMT of GC cells by regulating the expression of the epithelial and mesenchymal proteins E-cadherin and vimentin.
\end{abstract}

Correspondence to: Professor Zhen-Biao Mao, Department of Gastroenterology, Affiliated Hospital of Nantong University, 20 Xisi Road, Nantong, Jiangsu 226001, P.R. China

E-mail: mzb63@163.com

Professor Wei-Chang Chen, Department of Gastroenterology, The First Affiliated Hospital of Soochow University, 188 Shizi Street, Suzhou, Jiangsu 215006, P.R. China

E-mail: weichang_chen2014@163.com

Key words: gastric carcinoma, caudal-type homeobox transcription factor 2, cell proliferation, cell movement, epithelial-mesenchymal transition

\section{Introduction}

Although the incidence of gastric cancer (GC) has decreased substantially in most parts of the world due to advances in early diagnosis, eradication of Helicobacter pylori and changes in lifestyle, $\mathrm{GC}$ is one of the most frequently diagnosed malignant tumor types $(1,2)$. In Europe, GC was the fourth most common cause of cancer-associated mortality in 2012 (3). However, almost two-thirds of these cancers occur in developing countries, the incidence in China accounts for $\sim 42 \%$ of all cases and GC was the second most common cancer in 2009 (4,5). The prognosis for gastric cancer patients with advanced cancer is generally poor and hard to predict. To date, surgery has remained the primary treatment, following which the average five-year survival rate is only $20-25 \%$ (6). Although diagnostic techniques have improved, most patients with GC already have locally advanced disease, and early recurrence and metastasis after surgery still remain a major challenge $(7,8)$. Recently, epithelial- mesenchymal transition (EMT) has been noted as a critical event in the early step of cancer metastasis (9). EMT is considered to be correlated with the malignancy of cancer cells and responsible for cancer invasion and metastasis, as it promotes the detachment of cancer cells from the primary tumor areas, leading to invasion of the vasculature and colonization of distant organs with secondary tumors $(10,11)$.

Nuclear transcription factor CDX2 is a significant regulator of in the proliferation and differentiation of intestinal epithelial cells in fetal and adult tissues. CDX2 has specificity for enterocytes and has been employed for the diagnosis of primary and metastatic colorectal cancers (12). Moskaluk et al (13) assessed the expression of CDX2 in 745 cancer specimens from various anatomic sites by microarray analysis, which showed that $20-30 \%$ of carcinomas of the stomach were positive for CDX2, particularly intestinal-type GC (14). Several studies have reported that CDX2-positive GC patients had a higher survival rate than those who were CDX2-negative (15). In addition, a negative correlation between CDX2 expression and the depth of tumor invasion and lymph node metastasis was noted (16-18). A recent meta-analysis showed that CDX2 is a prognostic factor, which may be used as a marker of good outcome in patients with GC (19). However, the molecular mechanisms leading to the 
improved biological behavior and outcome due to CDX2 overexpression in GC patients have remained elusive. To address this issue, the present study assessed whether CDX2 was expressed on GC cells and whether overexpression of CDX2 was able to inhibit GC-cell growth and reverse the EMT in vitro and in vivo.

\section{Materials and methods}

Cell culture and transfection. The human GC cell lines AGS and MKN-45 (Cell Bank of the Chinese Academy of Sciences, Shanghai, China) was maintained in Dulbecco's modified Eagle's medium (DMEM; HyClone, UT, USA) supplemented with $10 \%$ fetal bovine serum (FBS; Tianhang Biological Technology Co., Ltd, Zhejiang, China), penicillin (100 U/ml) and streptomycin $(100 \mu \mathrm{g} / \mathrm{ml})$ (Gibco-BRL, Invitrogen Life Technologies, Inc., Carlsbad, CA, USA) at $37^{\circ} \mathrm{C}$ in a humidified $5 \% \mathrm{CO}_{2}$ incubator. The pEGFP-N1 plasmid (Clontech Laboratories, Inc., Mountainview, CA, USA) was used to construct the CDX2 expression vector. Total RNA was extracted from human GC AGS cells using TRIzol ${ }^{\circledR}$ (Invitrogen Life Technologies, Inc.).The resulting RNAs were treated with RNase-free DNase (Promega Corporation, Madison, WI, USA) and 800 ng RNA was reverse transcribed into cDNA using the PrimeScript RT Reagent kit (Takara Biotechnology Co.,Ltd.,Dalian, China), according to the manufacturer's instructions. CDX2 cDNA was amplified using a reverse transcription-polymerase chain reaction (RT-PCR) kit (Invitrogen Life Technologies, Inc.), according to the manufacturer's instructions. The complete cDNA sequence of CDX2 was amplified by RT-PCR using primers, which were synthesized by Sangon Biotech Co., Ltd. (Shanghai, China). The sequences of the primers were as follows: Forward 5'-TTTTCTCGAG ATGTACGTGAGCTACCTCCTG-3', which introduced an XhoI cleavage site sequence (CTGCTC), and reverse 5'-TTTT AAGCTTCTGGGTGACGGTGGGGTTTAG-3' which introduced a HindIII cleavage site sequence (CTTAAG). The CDX2 cDNA PCR product and pEGFP-N1 were digested using XhoI/HindIII (Fermentas, Thermo Fisher Scientific, Inc., Vilnius, Lithuania). The PCR amplification (Bio-Rad T100, Bio-Rad Laboratories, Inc., Hercules, CA, USA) conditions were as follows: Initial denaturation at $94^{\circ} \mathrm{C}$ for $2 \mathrm{~min}$, followed by 25 cycles of $94^{\circ} \mathrm{C}$ for $60 \mathrm{sec}, 55^{\circ} \mathrm{C}$ for $60 \mathrm{sec}$ and $72^{\circ} \mathrm{C}$ for $2 \mathrm{~min}$, followed by a final extension step at $72^{\circ} \mathrm{C}$ for $5 \mathrm{~min}$. Subsequently, $5 \mu \mathrm{l}$ PCR products were electrophoresed on $1 \%$ agarose gel. The PCR products were purified using the DNA Purification kit (Beyotime Institute of Biotechnology, Nantong, China), according to the manufacturer's instructions, and ligated into the cut vector to form pEGFP-N1-CDX2. Following ligation, the plasmid was transformed into E. coli $\mathrm{DH} 5 \alpha$ cells (Takara Biotechnology Co., Ltd.), and plated on solid lysogeny broth medium (containing kanamycin; Yaopharma Co., Ltd., Chongqing, China). Kanamycin-resistant colonies were cultured at $37^{\circ} \mathrm{C}$ overnight with agitation. The recombinant plasmid was prepared, and the sequences were verified by electrophoresis of the digested product. pEGFP-N1-CDX2 was transfected into GC MKN-45 cells using Lipofectamine ${ }^{\mathrm{TM}} 2000$ reagent (Invitrogen Life Technologies, Inc.) according to the manufacturer's instructions. Briefly, $24 \mathrm{~h}$ prior to transfection, cells were seeded into six-well plates $\left(5 \times 10^{5}\right.$ cells/ well $)$ and inoculated in complete medium without antibiotics $(2 \mathrm{ml} /$ well). At $70-80 \%$ confluence, the plasmid DNA (4.0 $\mu \mathrm{g} /$ well) and transfection reagent (10 $\mu \mathrm{l} /$ well) were diluted with RPMI-1640 (250 $\mu \mathrm{l})$ and incubated at room temperature for $5 \mathrm{~min}$. The transfection reagent and dilution of the plasmid DNA were then mixed and incubated at room temperature for 20-30 min. Next, the transfection complexes were filled into six-well plates, supplementary medium was added at $2 \mathrm{ml} /$ well and plates were cultured at $37^{\circ} \mathrm{C}$ in a humidified $5 \% \mathrm{CO}_{2}$ incubator. Four to six hours after transfection, the supernatant was replaced with DMEM containing $10 \%$ FBS followed by further cultivation.

RT-quantitative (q)PCR. The total RNA from cultured cells was extracted using the TRIzol ${ }^{\circledR}$ reagent extraction kit (Invitrogen Life Technologies, Inc.) according to the manufacturer's instructions. Amplification was performed in a 7500 Real-Time PCR System (Applied Biosystems, Thermo Fisher Scientific, Waltham, MA, USA) using the QuantiTect SYBR Green PCR kit (Qiagen, Hilden, Germany). PCR was performed as previously described using primers specific for $\beta$-actin and CDX2 (20). The $\beta$-actin gene was adopted as an internal control for all RT-qPCR reactions.

Western blot analysis. The cells were lysed using radioimmunoprecipitation buffer and phenylmethylsulfonyl fluoride (all Beyotime Institute of Biotechnology) for $30 \mathrm{~min}$ on ice. The protein extracts were subsequently centrifuged at $12,800 \mathrm{x} \mathrm{g}$ for $20 \mathrm{~min}$ at $4^{\circ} \mathrm{C}$, and the protein concentration was determined using a bicinchoninic acid protein assay kit (Beyotime Institute of Biotechnology). Equal amounts ( $40 \mu \mathrm{g})$ of protein from various samples were separated by $12 \%$ SDS-PAGE (Beyotime Institute of Biotechnology) and electro-transferred onto polyvinylidene fluoride (PVDF) membranes (EMD Millipore, Billerica, MA, USA) using the Mini Protean 3 system (Bio-Rad Laboratories, Inc.). PVDF membranes were blocked with phosphate-buffered saline (PBS) containing 5\% skimmed milk powder for $2 \mathrm{~h}$ and incubated with the following primary antibodies: Mouse anti-CDX2 monoclonal antibody (cat. no. 60243-1-Ig), rabbit anti-E-cadherin polyclonal antibody (cat. no. 20874-1-AP) and rabbit anti-vimentin polyclonal antibody (cat. no. 10366-1-AP) (1:2,000; all Proteintech Group, Inc., Chicago, IL, USA), as well as the internal control mouse anti- $\beta$-actin monoclonal antibody (1:2,000; cat. no. M20010; Abmart, Inc., Shanghai, China) at $4{ }^{\circ} \mathrm{C}$ overnight. The membranes were then incubated for $2 \mathrm{~h}$ at room temperature with horseradish peroxidase-conjugated anti-mouse (cat.no. 115-032-003) or anti-rabbit (cat. no. 111-035-003) immunoglobulin G secondary antibodies (Jackson ImmunoResearch Europe Ltd., Newmarket, UK), diluted at 1:5,000. The protein was visualized using an enhanced chemiluminescent detection system, according to the manufacturer's instructions (GE Healthcare Life Sciences, Little Chalfont, UK). Following chemiluminescence, the membrane was exposed to X-ray film (Eastman Kodak, Rochester, NY, USA), and ImageJ 1.37 software (National Institutes of Health, Bethesda, MD, USA) was used for grey value analysis. Relative amounts of proteins were quantified by absorbance analysis, and the level was normalized to $\beta$-actin.

Cell counting kit (CCK)-8 assay. Cell proliferation was determined using a CCK-8 (Beyotime Institute of Biotechnology) according to the manufacturer's instructions. Briefly, cells $\left(5 \times 10^{7}\right.$ cells/l) suspended in DMEM (100 $\left.\mu \mathrm{l}\right)$ containing 10\% 

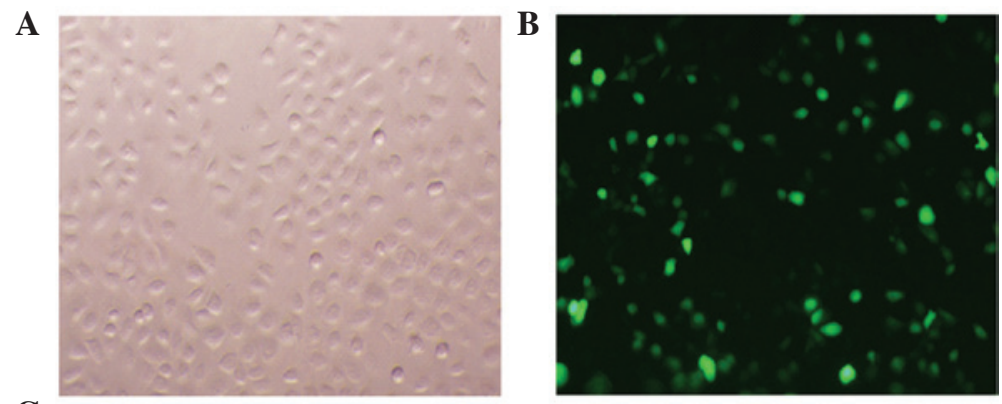

C

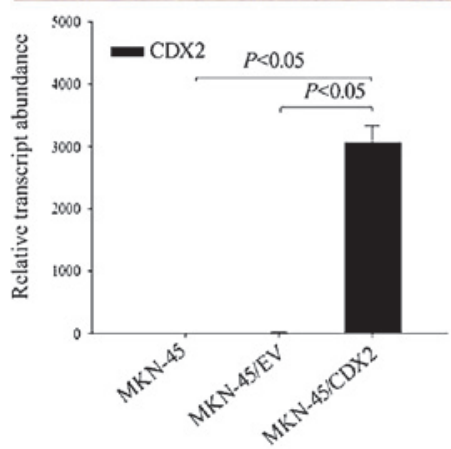

D

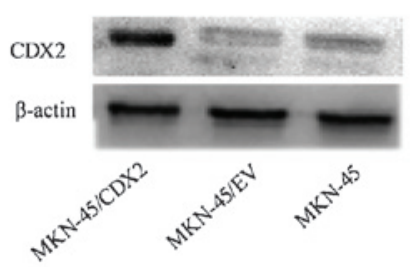

Figure 1. Transfection efficiency was observed under an inverted microscope. (A and B) Microscopic analysis showed that $>80 \%$ of MKN45 cells were labeled with GFP and had been successfully transfected with pEGFP-N1-CDX2 (magnification, x200). (C and D) mRNA and protein levels of CDX2 in MKN45 cells were validated by reverse transcription quantitative polymerase chain reaction and western blot analysis, respectively. Compared with the control group (MKN45/EV and MKN45), markedly higher levels of CDX2 mRNA and protein were expressed in MKN45/CDX2 cells $(\mathrm{P}<0.05)$. Values are expressed as the mean \pm standard deviation. EGFP, enhanced green fluorescence protein; EV, empty vector.

A

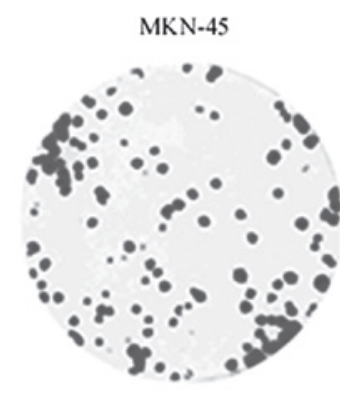

MKN-45/EV

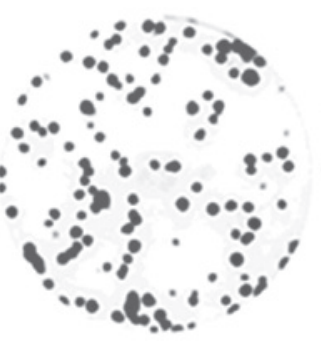

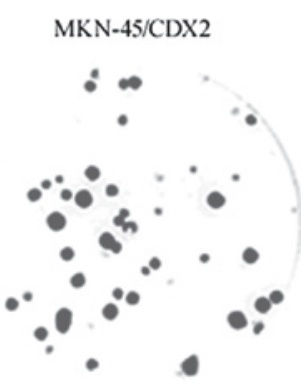

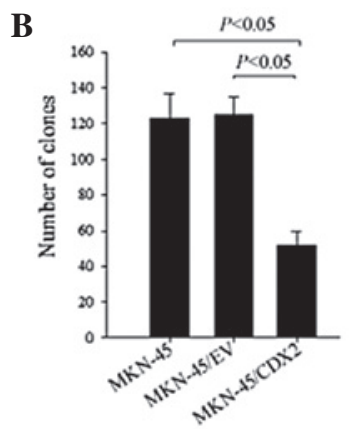

Figure 2. (A) Cell proliferation ability was measured by colony formation assay (magnification, x100). (B) Compared with the MKN45/EV and MKN45 cells, the number of colonies formed by MKN45/CDX2 cells after two weeks of culture was significantly decreased $(\mathrm{P}<0.05)$. Values are expressed as the mean \pm standard deviation. EV, empty vector.

FBS were seeded in 96-well plates and incubated for 24, 48 or $72 \mathrm{~h}$. CCK-8 solution (10 $\mu \mathrm{l})$ was added to each well and the cultures were incubated at $37^{\circ} \mathrm{C}$ and $5 \% \mathrm{CO}_{2}$ for $2.5 \mathrm{~h}$. The absorbance was determined at $450 \mathrm{~nm}$ using a multimode microplate reader (Varioskan Flash; Thermo Fisher Scientific).

Colony formation assay. The colony formation assay was performed as described previously (21). Briefly, 100 cells were seeded onto each of the $35-\mathrm{mm}$ dishes and allowed to grow for two weeks to assess colony formation on the culture plates. Cell colonies were stained with $0.5 \%$ crystal violet (Amresco LLC, Solon, OH, USA) for $5 \mathrm{~min}$ at room temperature. Colonies of $>50$ cells were counted under an upright light microscope (BX51; Olympus Corporation, Tokyo, Japan; magnification, x100) and the mean value was calculated.
Migration and invasion assays. For the cell migration ability assays, $5 \times 10^{5}$ cells transiently transfected for $24 \mathrm{~h}$ in the logarithmic growth phase were seeded onto six-well plates. The cells were cultured to form confluent cell monolayers and then wounded by performing a horizontal scratch with a pipette tip. Non-adherent cells were gently removed by rinsing with PBS. Wound closure was monitored using an inverted fluorescence microscope (IX71; Olympus Corporation; magnification, x100) at various time-points. Migration activity was calculated as the mean distance between the edges of three points. Healing rate $=$ (mean original distance - mean distance at a time-point)/mean original distance $\mathrm{x} 100 \%$.

For the invasion assays, $1 \times 10^{5}$ cells transiently transfected for $48 \mathrm{~h}$ were seeded in the top chamber of a Transwell plate containing a Matrigel-coated membrane (24-well insert; $8 \mathrm{~mm}$ pore size; BD Biosciences, Franklin Lakes, NJ, USA). 
Serum-free medium was used for the cells in the upper chamber containing the cells, and medium supplemented with $20 \%$ (v/v) FBS was used as a chemoattractant in the lower chamber. The cells were incubated for $24 \mathrm{~h}$ at $37^{\circ} \mathrm{C}$ and in a $5 \%(\mathrm{v} / \mathrm{v}) \mathrm{CO}_{2}$ incubator. Following incubation, the non-invading cells were removed from the upper side of the Transwell membrane filter inserts using cotton-tipped swabs. The invaded cells on the lower side of the inserts were stained with Giemsa, according to the manufacturer's instructions (Wright-Giemsa Stain kit; Nanjing Jiancheng Bioengineering Institute, Nanjing, China). Visual fields $(n=15)$ of each insert were randomly counted under an upright light microscope (BX51; Olympus Corporation) and the mean value was calculated.

Tumorigenic assay in nude mice. The present study was approved by the ethics committee of the Affiliated Hospital of Nantong University (Nantong, China). The experiments were performed according to the Nantong University Institutional Animal Care and Use Committee. To analyze the tumorigenicity of GC cells in vivo, MKN45 cells at twenty-four hours after transfection were diluted to $1: 4$ for passage and MKN45/CDX2 stable cell lines were screened by administration of G418 (Invitrogen Life Technologies, Inc.). Four-week-old male or female BALB/c nu/nu nude mice were purchased from the Center of Laboratory Animal Science, Chinese Academy of Medical Science (Shanghai, China). According to the experimental animal guidelines, the mice were maintained in $24^{\circ} \mathrm{C}$ temperature-controlled and specific pathogen-free conditions; they were housed separately, and were fed sterilized food and autoclaved water. The mice were subcutaneously injected in the dorsal flanks with $2 \times 10^{7}$ MKN45/CDX2, empty-vector (EV) transfected MKN45/EV or native MKN45 cells, respectively, suspended in $200 \mu \mathrm{l}$ PBS. Mice were weighed, and tumor width and length were measured with calipers three times a week. Mice were sacrificed at seven weeks after cell inoculation. Tumor volume was calculated using the formula $\mathrm{V}\left(\mathrm{mm}^{3}\right)=\left(\right.$ width ${ }^{2} \mathrm{x}$ length $) / 2$. The mice were sacrificed by cervical dislocation 7 weeks after cell inoculation, and the tumor tissue samples were taken to assess the protein expression levels of vimentin and E-cadherin. The tumor tissues were homogenized using an ultrasonic processor (S-450D; Branson Ultrasonics Corporation, Danbury, CT, USA) for tissue lysate extraction, the tissue lysates were centrifuged at $12,800 \mathrm{x} \mathrm{g}$ for $20 \mathrm{~min}$ at $4^{\circ} \mathrm{C}$ and the supernatants were collected. Equal quantities $(150 \mu \mathrm{g})$ of protein were loaded per lane for western blot analysis.

Statistical analysis. All experiments were repeated at least three times. Statistical analysis was performed using SPSS 19.0 (SPSS, Inc., International Business Machines, Armonk, NY, USA). Values are expressed as the mean \pm standard deviation and groups were compared using one-way analysis of variance. $\mathrm{P}<0.05$ was considered to indicate a statistically significant difference.

\section{Results}

Construction of the pEGFP-N1-CDX2 recombinant vector and transient transfection. A previous study showed that the expression of CDX2 on MKN-45 cells was low (19).

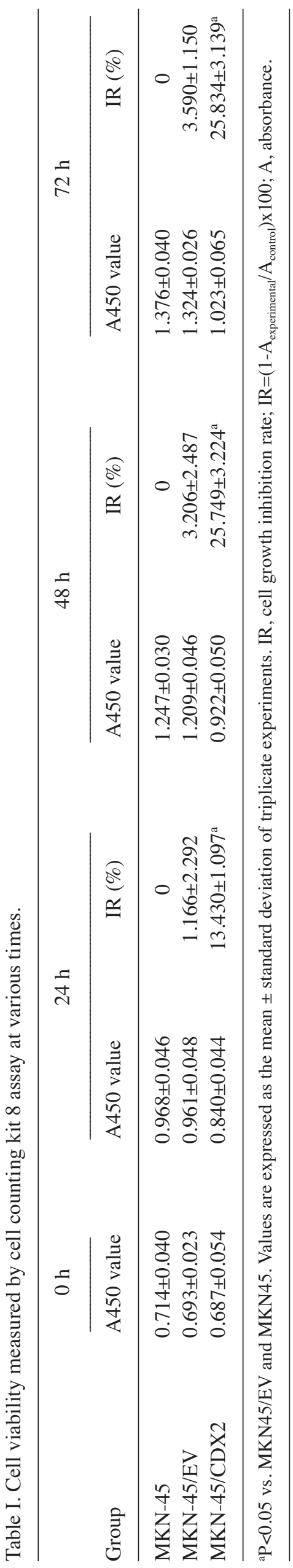


A

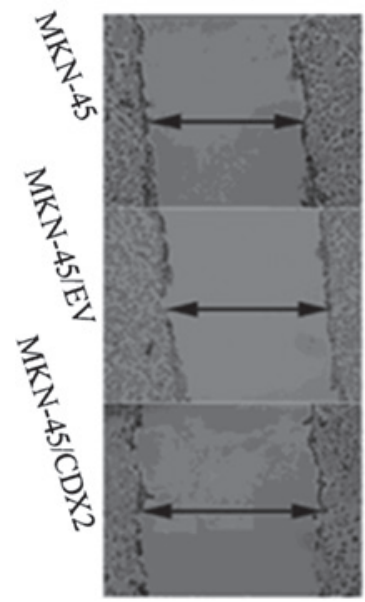

B
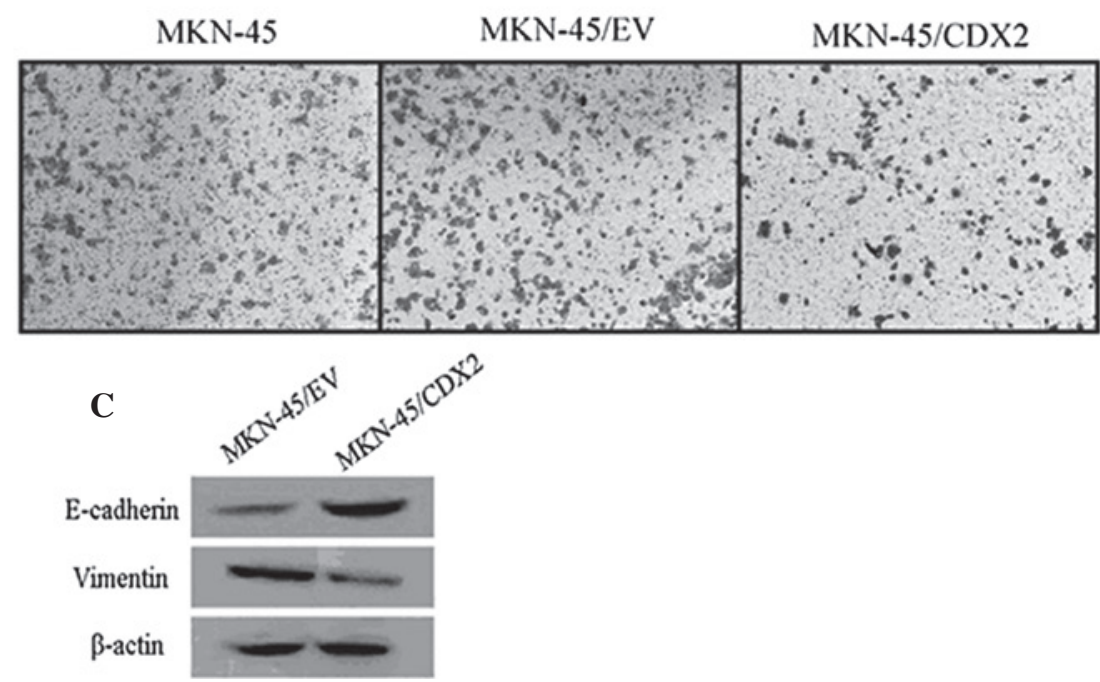

$48 \mathrm{~h}$

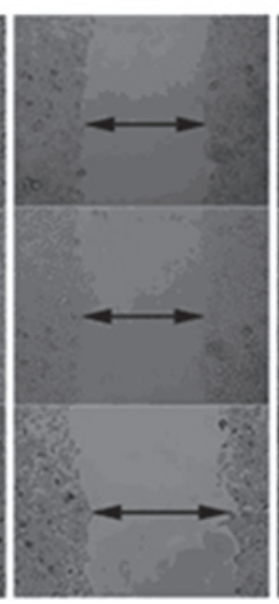

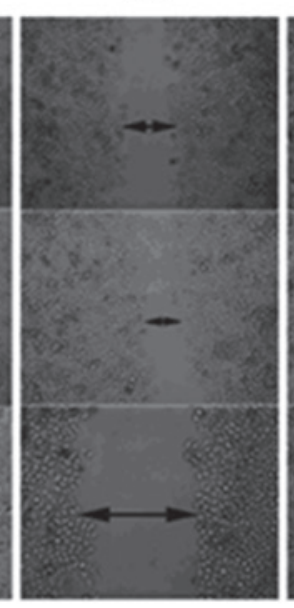

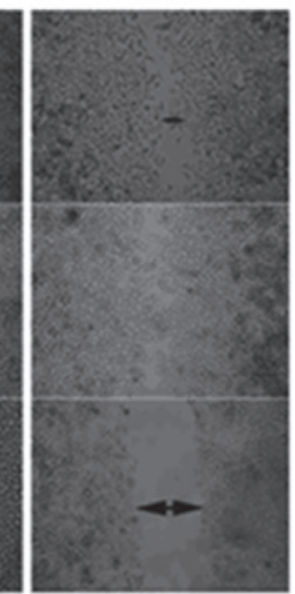

$\mathrm{MKN}-45 / \mathrm{CDX} 2$
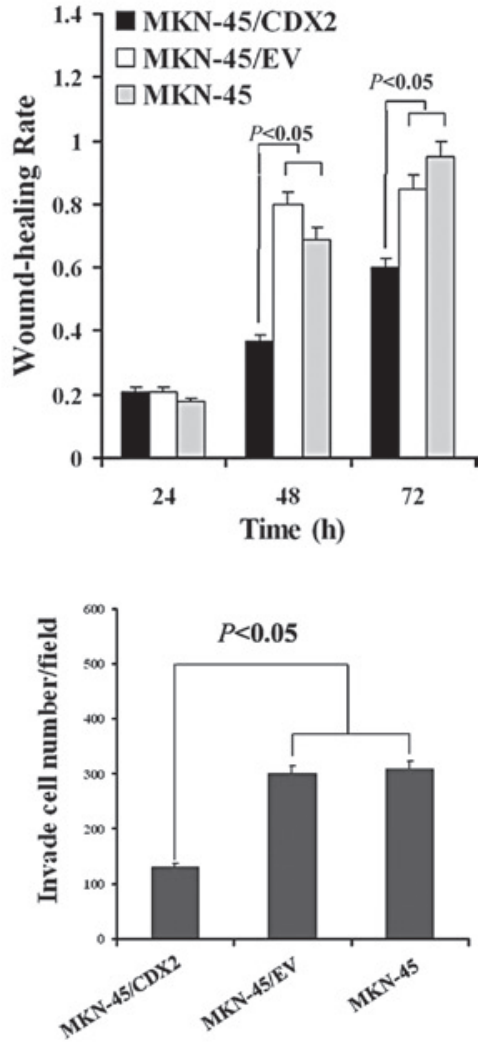

Figure 3. CDX2 inhibits migration, invasion and reverses the epithelial-to-mesenchymal transition in gastric cancer cells in vitro. (A) The scratch-wound assay indicated that MKN45/CDX2 cells showed lower migration ability at 48 and $72 \mathrm{~h}$ time-points compared with MKN45/EV and MKN45 cells (P<0.05). (B) Transwell ${ }^{\circledR}$ assay results showed that in the MKN45/EV and MKN45 groups, the numbers of cells that had invaded through the membrane of the Matrigel chamber were $\sim 2.3$-fold higher than those in the MKN45/CDX2 group ( $\mathrm{P}<0.05)$. (Magnification, $\mathrm{x} 100)$. (C) Western blot analysis showed that MKN45/CDX2 cells exhibited a significant upregulation of E-cadherin protein expression and a significant downregulation of vimentin protein expression $(\mathrm{P}<0.05)$. Values are expressed as the mean \pm standard deviation.

To examine the effects of CDX2 on gastric cancer cells in vitro, the plasmid pEGFP-N1 was used to construct the CDX2 expression vector, pEGFP-N1-CDX2, to be transfected into the MKN45 cells to create the engineered cell line MKN45/CDX2 with forced overexpression of CDX2 protein. A control cell line was transfected with the empty vector and named as MKN45/EV. The transfection efficiency was confirmed by fluorescence microscopy observation. The results showed that $>80 \%$ cells were labeled with EGFP, indicating that MKN45 cells had been successfully transfected with pEGFP-N1-CDX2 (Fig. 1A and B). mRNA and protein levels of CDX2 in MKN45 cells were validated by RT-qPCR and western blot analysis, respectively. Compared with the control groups (MKN45/EV and MKN45), CDX2 mRNA and protein expression were significantly enhanced in MKN45/CDX2 cells ( $\mathrm{P}<0.05$; Fig. $1 \mathrm{C}$ and $\mathrm{D})$.

CDX2 suppresses gastric cancer cell proliferation. To investigate the effects of CDX2 overexpression on the growth of MKN45 cells, cell viability was assessed using the CCK-8 assay. The results showed that high expression of CDX2 in the MKN45/CDX2 group significantly inhibited the cell proliferation compared with that in the MKN45/EV group and the untransfected MKN45 group ( $\mathrm{P}<0.05$; Table I). These results were further supported by the colony formation assay. The three cell lines were all able to form colonies in soft agarose; however, the number of colonies formed by MKN45/CDX2 cells after two weeks of culture was significantly decreased compared with that in the MKN45/EV and MKN45 cells $(\mathrm{P}<0.05$; Fig. 2A and B).

CDX2 inhibits migration and invasion and reverses the EMT phenotype of gastric cancer cells in vitro. The scratch-wound assay was used to compare the scratch width at $0,24,48$ and $72 \mathrm{~h}$. The results showed that MKN45/CDX2 cells had a decreased migratory ability at the 48 and $72 \mathrm{~h}$ time-points compared to that of the control groups MKN45/EV and MKN45 $(\mathrm{P}<0.05$; Fig. 3A). Furthermore, the invasion ability of three groups was assessed using a Transwell ${ }^{\circledR}$ assay. The number of cells that had transgressed through the membrane was counted 
Table II. Tumor volume.

\begin{tabular}{lcrr}
\hline Weeks after injection & MKN-45/CDX2 $\left(\mathrm{mm}^{3}\right)$ & MKN-45/EV $\left(\mathrm{mm}^{3}\right)$ & MKN-45 $\left(\mathrm{mm}^{3}\right)$ \\
\hline 1 & $28.02 \pm 3.52^{\mathrm{a}}$ & $62.09 \pm 1.89$ & $59.40 \pm 5.88$ \\
2 & $38.44 \pm 3.13^{\mathrm{a}}$ & $170.60 \pm 4.98$ & $103.96 \pm 8.10$ \\
3 & $83.69 \pm 4.36^{\mathrm{a}}$ & $313.10 \pm 13.09$ & $379.4 \pm 18.30$ \\
4 & $151.15 \pm 4.66^{\mathrm{a}}$ & $361.27 \pm 32.12$ & $620.08 \pm 16.65$ \\
5 & $218.58 \pm 8.68^{\mathrm{a}}$ & $857.15 \pm 18.20$ & $989.09 \pm 24.20$ \\
6 & $291.62 \pm 7.97^{\mathrm{a}}$ & $1092.84 \pm 19.53$ & $1181.01 \pm 21.97$ \\
7 & $352.88 \pm 26.11^{\mathrm{a}}$ & $1205.06 \pm 34.08$ & $1329.99 \pm 24.16$
\end{tabular}

Data are expressed as the mean \pm standard deviation. ${ }^{a} \mathrm{P}<0.05$, vs. MKN-45/EV and MKN-45.

A

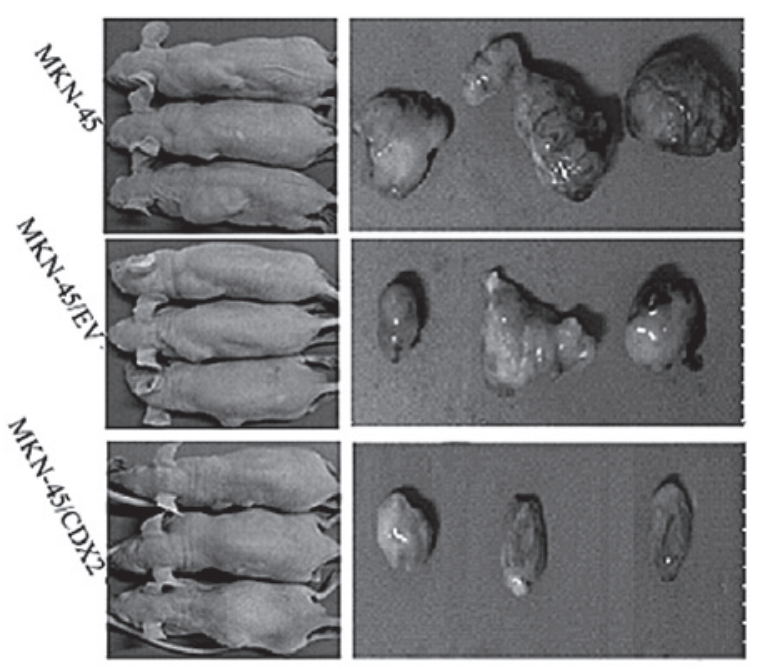

B

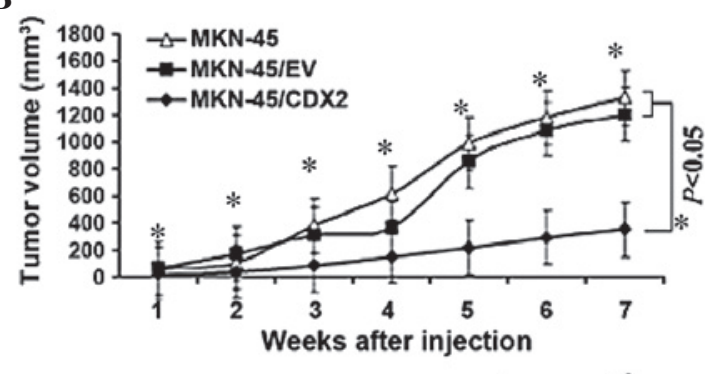

C

E-cadherin

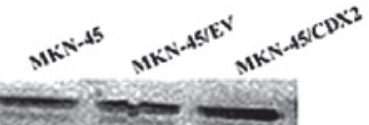

Vimentin

$\beta$-actin

Figure 4. CDX2 regresses gastric tumor xenograft growth and inhibits epithelial-to-mesenchymal transition in nude mice. (A and B) Animal tumorigenicity assays showed that, compared with mice injected with the control MKN45/EV and MKN45 cells, animals injected with MKN45/CDX2 cells developed smaller and slower-growing tumors ( $\mathrm{P}<0.05)$. (C) Western blot analysis showed that MKN45/CDX2 cells exhibited a significant upregulation of E-cadherin protein and a significant downregulation of vimentin protein in nude mice $(\mathrm{P}<0.05)$. Values are expressed as the mean \pm standard deviation.

following transfection for $48 \mathrm{~h}$. The results showed that the numbers of MKN45/EV and MKN45 cells that had invaded through the membrane of the Matrigel chamber were 2.3 -fold higher than that in the MKN45/CDX2 group $(\mathrm{P}<0.05$; Fig. $3 \mathrm{~B})$.

To study the effects of CDX2 on the EMT of MKN45 cells, the expression of E-cadherin and vimentin was determined using western blot analysis. MKN45/CDX2 cells overexpressing CDX2 exhibited a significant upregulation of E-cadherin protein expression and a significant downregulation of vimentin protein expression $(\mathrm{P}<0.05$; Fig. $3 \mathrm{C})$.

CDX2 regresses gastric tumor xenograft growth and inhibits EMT in nude mice. To assess the pathophysiological role of CDX2 in gastric tumor xenograft growth, in vivo tumorigenicity assays were performed, which showed that mice injected with MKN45/CDX2 cells developed smaller and slower-growing tumors when compared to those in animals injected with the control MKN45/EV and MKN45 cells $(\mathrm{P}<0.05$; Fig. 4A and B; Table II). Furthermore, western blot analysis of the tumor tissue showed that MKN45/CDX2 cells exhibited a significant upregulation of E-cadherin protein and a significant downregulation of vimentin protein in nude mice $(\mathrm{P}<0.05$; Fig. 4C).

\section{Discussion}

The present study used the plasmid pEGFP-N1 to construct a CDX2 expression vector. MKN45 cells were successfully transfected with pEGFP-N1-CDX2, and CDX2 was overexpressed in MKN45/CDX2 cells in vitro. Compared with the MKN45/EV group and MKN45 group, the CCK-8 assay revealed that high expression of CDX2 in the MKN45/CDX2 group significantly inhibited cell proliferation, and a colony formation assay also showed that the number of colonies formed by MKN45/CDX2 cells after two weeks of culture was significantly decreased. Furthermore, migration and invasion assays demonstrated that MKN45/CDX2 cells showed a lower migration and invasion ability compared to those in the MKN45/EV and MKN45 control groups. All of these results suggested that in vitro, forced expression of CDX2 in MKN45/CDX2 cells inhibited GC-cell growth and proliferation, as well as reduced migration and invasion. These results are consistent with those of a previous 
study (22), while the pathophysiological role of CDX2 in gastric tumors had not been reported previously. In the present study, in vivo tumorigenicity assays showed that mice injected with MKN45/CDX2 cells developed smaller and slower-growing tumors compared to those in animals injected with MKN45/EV and MKN45 cells.

Abnormal proliferation of epithelial cells and angiogenesis are hallmarks of the initiation and early growth of primary epithelial cancer (23). With further onset of the disease, cancer cells acquire invasive properties at the last stages of the multi-step process eventually leading to metastatic dissemination, which has life-threatening consequences. Several studies have proposed the activation of an EMT program as the crucial mechanism for the acquisition of malignant phenotypes by epithelial cancer cells $(24,25)$. During the EMT, a polarized epithelial cell, which normally interacts with the basement membrane via its basal surface, undergoes multiple biochemical changes in order to transform into a mesenchymal cell phenotype, which is characterized by an enhanced migratory capacity, invasiveness, elevated resistance to apoptosis and markedly increased production of ECM components (9). As cancer cells lose their epithelial phenotype and acquire a mesenchymal phenotype, intercellular adhesions are decreased, leading to their detachment from the tumor mass and invasion of neighboring tissue, blood or lymph vessels, which is a basis for the development of secondary tumors $(25,26)$.

Cells undergoing EMT lose their structural adhesion components, including E-cadherin, and gain mesenchymal cell markers such as vimentin, which are hallmarks of the EMT $(9,27)$. It has been reported that aberrant activation of the EMT contributes to tumour progression and metastasis, and the EMT has been associated with poor prognosis in several types of cancer (28-32).

CDX2 is a nuclear homeobox transcription factor that belongs to the caudal-related family of CDX homeobox genes (11). Several studies have reported that loss of the expression of epithelial marker CDX2 in colorectal cancer correlated with high tumor grade, microsatellite instability, positive lymph node metastasis or advanced tumor stage (33-35). Furthermore, loss of CDX2 and E-cadherin as well as vimentin overexpression were observed in rhabdoid colorectal tumors but not in normal mucosa or adenomas (36). These results indicated that loss of CDX2 contributed to aggressive tumor behavior and increase the likelihood of metastatic disease. A recent study suggested that there was a significant link between sialyl Lewis $\mathrm{x}$ and sialyl Lewis a $\left(\mathrm{sLe}^{\mathrm{x} / \mathrm{a}}\right)$ expression and the EMT in colon cancer cells; furthermore c-Myc and CDX2 were shown to have a pivotal role in regulating $\mathrm{sLe}^{\mathrm{x} / \mathrm{a}}$ expression during the EMT (37).

Although certain evidence has indicated that CDX2 is a tumor suppressor in GC (38), the association between CDX2 and metastasis has remained to be fully elucidated. A clinical study by Okayama et al (17) reported that the loss of CDX2 expression in GC tissues was significantly correlated with lymph node metastasis. Forced expression of CDX2 in GC cells has been reported to inhibit proliferation and induce apoptosis in vitro (22), while the association between CDX2 expression and EMT has remained elusive.

The present study demonstrated in vitro and in vivo that MKN45/CDX2 cells overexpressing CDX2 exhibited a significant upregulation of E-cadherin protein expression and a significant downregulation of vimentin protein expression. Numerous animal studies and cell experiments have demonstrated that cancer cells can acquire a mesenchymal phenotype and express mesenchymal markers, including $\alpha$-smooth muscle actin, fibroblast-specific protein 1, vimentin and desmin (39). These cells are typically found at the invasive front of primary tumors and are considered to be the cells that eventually enter into subsequent steps of the invasion-metastasis cascade, including intravasation, transport through the circulation, extravasation, formation of micrometastases, and ultimately the growth of small colonies into macroscopic metastases $(24,40,41)$.

In conclusion, the results of the present study demonstrated that forced expression of CDX2 in human GC cells is capable to inhibit growth and invasion, and reverse the EMT in vitro and in vivo. The reduced capacities of migration and invasion may be correlated with the reversal of the EMT. However, the precise underlying molecular mechanisms remain elusive and require further study.

\section{Acknowledgements}

This study was supported by the Technologies Research Program of the Affiliated Hospital of Nantong University (no. TDFY0343).

\section{References}

1. Bertuccio P, Chatenoud L, Levi F, Praud D, Ferlay J, Negri E, Malvezzi M and La Vecchia C: Recent patterns in gastric cancer: A global overview. Int J Cancer 125: 666-673, 2009.

2. Jemal A, Bray F, Center MM, Ferlay J, Ward E and Forman D: Global cancer statistics. CA Cancer J Clin 61: 69-90, 2011.

3. Ferlay J, Steliarova-Foucher E, Lortet-Tieulent J, Rosso S, Coebergh JW, Comber H, Forman D and Bray F: Cancer incidence and mortality patterns in Europe: Estimates for 40 countries in 2012. Eur J Cancer 49: 1374-1403, 2013.

4. Yang L: Incidence and mortality of gastric cancer in China. World J Gastroenterol 12: 17-20, 2006.

5. Chen W, Zheng R, Zhang S, Zhao P, Li G, Wu L and He J: Report of incidence and mortality in China cancer registries, 2009. Chin J Cancer Res 25: 10-21, 2013.

6. Zeng H, Zheng R, Guo Y, Zhang S, Zou X, Wang N, Zhang $\mathrm{L}$, Tang J, Chen J, Wei K, et al: Cancer survival in China, 2003-2005: A population-based study. Int J Cancer 136: 1921-1930, 2015.

7. Shi Y and Zhou Y: The role of surgery in the treatment of gastric cancer. J Surg Oncol 101: 687-692, 2010.

8. Meyer $\mathrm{HJ}$ and Wilke $\mathrm{H}$ : Treatment strategies in gastric cancer. Dtsch Arztebl Int 108: 698-705, 2011.

9. Kalluri R and Weinberg RA: The basics of epithelial-mesenchymal transition. J Clin Invest 119: 1420-1428, 2009.

10. Celià-Terrassa T, Meca-Cortés $\mathrm{O}$, Mateo $\mathrm{F}$, de Paz AM, Rubio N, Arnal-Estapé A, Ell BJ, Bermudo R, Díaz A, Guerra-Rebollo M, et al: Epithelial-mesenchymal transition can suppress major attributes of human epithelial tumor-initiating cells. J Clin Invest 122: 1849-1868, 2012.

11. Chung JY, Davis JA, Price BD, Staley DM, Wagner MV, Warner SL, Bearss DJ and Hansen MD: Competitive enhancement of HGF-induced epithelial scattering by accessory growth factors. Exp Cell Res 317: 307-318, 2011

12. Saad RS, Ghorab Z, Khalifa MA and Xu M: CDX2 as a marker for intestinal differentiation: Its utility and limitations. World J Gastrointest Surg 3: 159-166, 2011.

13. Moskaluk CA, Zhang H, Powell SM, Cerilli LA, Hampton GM and Frierson HF Jr: Cdx2 protein expression in normal and malignant human tissues: An immunohistochemical survey using tissue microarrays. Mod Pathol 16: 913-919, 2003.

14. Park do Y, Srivastava A, Kim GH, Mino-Kenudson M, Deshpande V, Zukerberg LR, Song GA and Lauwers GY: CDX2 expression in the intestinal-type gastric epithelial neoplasia: Frequency and significance. Mod Pathol 23: 54-61, 2010. 
15. Song JH, Kim CJ, Cho YG, Chae JS, Cao Z, Nam SW, Lee JY and Park WS: Genetic alterations of the Cdx2 gene in gastric cancer. APMIS 116: 74-80, 2008.

16. Mizoshita T, Tsukamoto T, Nakanishi H, Inada K, Ogasawara N, Joh T, Itoh M, Yamamura Y and Tatematsu M: Expression of Cdx2 and the phenotype of advanced gastric cancers: Relationship with prognosis. J Cancer Res Clin Oncol 129: 727-734, 2003.

17. Okayama H, Kumamoto K, Saitou K, Hayase S, Kofunato Y, Sato Y, Miyamoto K, Nakamura I, Ohki S, Sekikawa K, et al: CD44v6, MMP-7 and nuclear Cdx2 are significant biomarkers for prediction of lymph node metastasis in primary gastric cancer. Oncol Rep 22: 745-755, 2009.

18. Qin R, Wang NN, Chu J and Wang X: Expression and significance of homeodomain protein $\mathrm{Cdx} 2$ in gastric carcinoma and precancerous lesions. World J Gastroenterol 18: 3296-3302, 2012.

19. Wang XT, Wei WY, Kong FB, Lian C, Luo W, Xiao Q and Xie YB: Prognostic significance of $\mathrm{Cdx} 2$ immunohistochemical expression in gastric cancer: A meta-analysis of published literatures. J Exp Clin Cancer Res 31: 98, 2012

20. Zhang JF, Zhang JG, Kuai XL, Zhang H, Jiang W, Ding WF Li ZL, Zhu HJ and Mao ZB: Reactivation of the homeotic tumor suppressor gene CDX2 by 5-aza-2'-deoxycytidine-induced demethylation inhibits cell proliferation and induces caspase-independent apoptosis in gastric cancer cells. Exp Ther Med 5: 735-741, 2013

21. Franken NA, Rodermond HM, Stap J, Haveman J and van Bree C: Clonogenic assay of cells in vitro. Nat Protoc 1: 2315-2319, 2006

22. Xie Y, Li L, Wang X, Qin Y, Qian Q, Yuan X and Xiao Q: Overexpression of $\mathrm{Cdx} 2$ inhibits progression of gastric cancer in vitro. Int J Oncol 36: 509-516, 2010.

23. Hanahan D and Weinberg RA: Hallmarks of cancer: The next generation. Cell 144: 646-674, 2011.

24. Thiery JP: Epithelial-mesenchymal transitions in tumour progression. Nat Rev Cancer 2: 442-454, 2002.

25. Ksiażkiewicz M, Markiewicz A and Zaczek AJ: Epithelial-mesenchymal transition: A hallmark in metastasis formation linking circulating tumor cells and cancer stem cells. Pathobiology 79: 195-208, 2012.

26. Matsuoka J, Yashiro M, Doi Y, Fuyuhiro Y, Kato Y, Shinto O, Noda S, Kashiwagi S, Aomatsu N, Hirakawa T, et al: Hypoxia stimulates the EMT of gastric cancer cells through autocrine TGFß signaling. PLoS One 8: e62310, 2013.

27. Thiery JP, Acloque H, Huang RY and Nieto MA: Epithelial-mesenchymal transitions in development and disease. Cell 139: 871-890, 2009.

28. Elloul S, Vaksman O, Stavnes HT, Trope CG, Davidson B and Reich R: Mesenchymal-to-epithelial transition determinants as characteristics of ovarian carcinoma effusions. Clin Exp Metastasis 27: 161-172, 2010
29. Kumarswamy R, Mudduluru G,Ceppi P,Muppala S, Kozlowski M, Niklinski J, Papotti M and Allgayer H: MicroRNA-30a inhibits epithelial-tomesenchymal transition by targeting Snail and is downregulated in non-small cell lung cancer. Int J Cancer 130: 2044-2053, 2012

30. Chen ZL, Zhao XH, Wang JW, Li BZ, Wang Z, Sun J, Tan FW, Ding DP, Xu XH, Zhou F, et al: microRNA-92a promotes lymph node metastasis of human esophageal squamous cell carcinoma via E-cadherin. J Biol Chem 286: 10725-10734, 2011.

31. Sarrio D, Rodriguez-Pinilla SM, Hardisson D, Cano A, Moreno-Bueno G and Palacios J: Epithelial-mesenchymal transition in breast cancer relates to the basal-like phenotype. Cancer Res 68: 989-997, 2008.

32. Korpal M, Ell BJ, Buffa FM, Ibrahim T, Blanco MA, Celià-Terrassa T, Mercatali L, Khan Z, Goodarzi H, Hua Y, et al: Direct targeting of Sec23a by miR-200s influences cancer cell secretome and promotes metastatic colonization. Nat Med 17: 1101-1108, 2011.

33. Kaimaktchiev V, Terracciano L, Tornillo L, Spichtin H, Stoios D, Bundi M, Korcheva V, Mirlacher M, Loda M, Sauter G, et al: The homeobox intestinal differentiation factor CDX2 is selectively expressed in gastrointestinal adenocarcinomas. Mod Pathol 17: 1392-1399, 2004

34. Choi BJ, Kim CJ, Cho YG, Song JH, Kim SY, Nam SW, Lee SH, Yoo NJ, Lee JY and Park WS: Altered expression of CDX2 in colorectal cancers. APMIS 114: 50-54, 2006

35. Bakaris S, Cetinkaya A, Ezberci F and Ekerbicer H: Expression of homeodomain protein CDX2 in colorectal adenoma and adenocarcinoma. Histol Histopathol 23: 1043-1047, 2008.

36. Pancione M, Remo A, Sabatino L, Zanella C, Votino C, Fucci A, Di Blasi A, Lepore G, Daniele B, Fenizia F, et al: Right-sided rhabdoid colorectal tumors might be related to the serrated pathway. Diagn Pathol 8: 31, 2013.

37. Sakuma K, Aoki M and Kannagi R: Transcription factors c-Myc and CDX2 mediate E-selectin ligand expression in colon cancer cells undergoing EGF/bFGF-induced epithelial-mesenchymal transition. Proc Natl Acad Sci USA 109: 7776-7781, 2012.

38. Guo RJ, Suh ER and Lynch JP: The role of Cdx proteins in intestinal development and cancer. Cancer Biol Ther 3: 593-601, 2004.

39. Yang J and Weinberg RA: Epithelial-mesenchymal transition: At the crossroads of development and tumor metastasis. Dev Cell 14: 818-829, 2008.

40. Fidler IJ and Poste G: The 'seed and soil' hypothesis revisited. Lancet Oncol 9: 808, 2008.

41. Brabletz T, Jung A, Reu S, Porzner M, Hlubek F, Kunz-Schughart LA, Knuechel R and Kirchner T: Variable beta-catenin expression in colorectal cancers indicates tumor progression driven by the tumor environment. Proc Natl Acad Sci USA 98: 10356-10361, 2001. 